\title{
Causas de muerte evitables y su contribución al incremento en la esperanza de vida. Una interpretación sociodemográfica. El caso de la frontera norte, 1980-1990*
}

\section{Carlos Antonio García Molina** María Victoria López López ${ }^{* * *}$}

Los resultados que aquí se presentan cuestionan la afirmación de que "el cambio de estructura de la mortalidad por causas en México está inmerso en un proceso de transición epidemiológica". Cuando se conciben las causas de muerte como el resultado de procesos mórbidos que pudieron haber sido evitados o al menos que no evolucionaran hacia desenlaces fatales, con distintos tipos de medidas económicas, sociales, de servicios de salud y los avances en el conocimiento científico y tecnológico en salud, queda clara la existencia de una determinación estructural que impide que amplios sectores de la población transiten hacia "perfiles epidemiológicos modernos".

Este trabajo es parte de una investigación que busca aportar al conocimiento del proceso salud-enfermedad-muerte en la frontera norte, entendiendo ésta como un subproducto de la estructura socioeconómica de una formación social específica que determina la forma de enfermar y morir, y facilitar a nivel regional y (o) sectorial, el diseño de acciones y políticas tendientes a mejorar las condiciones de salud de su población.

Se utilizaron las bases de datos anuales sobre defunciones, entre 1979 y 1991, generadas por el INEGI y la DGE-SSA para los estados de Baja California, Coahuila, Chihuahua, Sonora y Tamaulipas. Se ajustaron las defunciones según el procedimiento propuesto por Preston-Coale y se construyeron tablas de vida para 1980 y 1990. Se encontraron los aportes de ios grupos de causas evitables por sexo y edad a las ganancias en la esperanza de vida en el periodo según el procedimiento de Pollard.

Entre los hallazgos se destacan: una ganancia de 4.1 años en la esperanza de vida debido, entre otras causas, a una leve disminución relativa de muertes por causas que pudieron haber sido evitadas. Éstas todavía tienen una alta contribución al total de muertes (alrededor de 50\%). En contra de lo esperado, el género masculino disminuyó en .4 años la diferencia en la esperanza de vida con respecto a sus congéneres (6.2 años en 1990). La sobremortalidad masculina sigue siendo explicada por este tipo de causas, en donde los accidentes y violencias aportan altos porcentajes principalmente en Baja California y Chihuahua.

Para 1990, se encontró una subestimación de $29 \%$ en la tasa de mortalidad infantil con respecto a las estadísticas vitales. Finalmente, fue posible

* Ponencia presentada en el VI Congreso Latinoamericano y VIII Congreso Mundial de Medicina Social. Guadalajara, 20 al 23 de marzo de 1994

** Cen tro Regional de Investigaciones Multidisciplinarias (CRIM-UNAM).

*** Escuela de Salud Pública de México (ESPM-INSP). 
construir grupos de alto riesgo que deberán ser prioritarios si se quieren alcanzar nuevamente ganancias importantes en la esperanza de vida.

Palabras claves: mortalidad, mortalidad por causas, evitabilidad.

\section{Introducción}

No cabe duda acerca del importante descenso de la mortalidad general e infantil ocurrida en el país y de que la estructura de la mortalidad por causas ha experimentado cambios. Sin embargo, se conoce poco acerca de cómo se da este proceso regionalmente, cómo afecta la estructura de la mortalidad por causas y cómo ellas definen perfiles de mortalidad específicos.

Se parte de considerar que los cinco estados fronterizos, Baja California, Coahuila, Chihuahua, Sonora y Tamaulipas, presentan a su interior y en conjunto formas de enfermar y de morir específicas de acuerdo con sus particulares procesos socioeconómicos. Se pretende construir perfiles de mortalidad con base en sus estructuras de mortalidad por causas y su evolución en el tiempo. Aunque difícil de definir, se entiende aquí la frontera norte como un espacio socioeconómico inserto en un proceso de internacionalización estructural (Negrete, 1990: 169-184).

La Clasificación Internacional de Enfermedades (CIE) (OMS, 1978) permite, además de considerar los daños a la salud según su localización anatómica y su fisiopatología -para lo que fue concebida-, ahondar en la comprensión de la distribución y los determinantes histórico-sociales de los procesos mórbidos. Se trata de hacer acercamientos a otras realidades diferentes a aquellas para las que fue creada.

Para avanzar en lo anterior se planteó retomar dicha clasificación y cualificarla reconstruyendo el dato de mortalidad por causas. Esta reconstrucción se refiere a organizar la información buscando que el dato se transforme en hecho epidemiológico, mediante la articulación de esta información con el análisis del contexto histórico-social (López, 1991).

Para ello rescatamos conceptos como los de evitabilidad (Taucher, 1978, 1980; García et al., 1994) que permiten un reagrupamiento de las causas de muerte factibles de concebir como partes de un proceso, que trasciende lo biológico y lo individual señalando su articulación y delimitación con las condiciones histórico-sociales, lo cual permite identificar problemas y plantear propuestas de transformación.

Este reagrupamiento define las enfermedades en evitables y difícilmente evitables según condiciones socioeconómicas, las ca- 
racterísticas de prestación de los servicios de salud, la calidad del diagnóstico médico y finalmente de los avances del conocimiento científico y técnico en salud.

Esta definición permite, por un lado, explicar la mortalidad como un resultado específico del proceso salud-enfermedad y, por otro, medir de manera indirecta las necesidades en salud y la forma como son atendidas por la política de salud pública, en particular, y por la respuesta social organizada, en general.

En oposición al exagerado uso y abuso de técnicas estadísticas "modernas", nos interesa explorar aquí el uso de técnicas demográficas aplicadas a información estadística secundaria y cómo ellas permiten analizar procesos tan complejos como los de saludenfermedad y muerte.

\section{Consideraciones teórico-metodológicas}

\section{Consideraciones generales}

Sin lugar a dudas, el análisis demográfico ha permitido avanzar en la descripción de la mortalidad como fenómeno. Ésta se ha convertido en objeto de estudio, y los especialistas han hecho énfasis en estimaciones confiables del nivel y sus tendencias, de cómo varía su cuantum según algunas características de población y según espacios socioeconómicos.

Este análisis se basa normalmente en estimaciones de mortalidad para grandes conglomerados de población: el país, urbano-rural, grandes regiones geográficas o grupos sociales homogeneizados con base en variables "determinantes" como la educación, el ingreso, la ocupación, etc. Los diferenciales de la mortalidad así encontrados, aunque en la mayoría de los casos son importantes y tienden a mantenerse en el espacio y en el tiempo, no permiten hacer consideraciones teóricas que ayuden a explicar relaciones causales del fenómeno, o mejor, sus sustentos teóricos no permiten pasar de la mortalidad como variable a la mortalidad como concepto con un mayor nivel de abstracción.

Un acercamiento a otras disciplinas de las ciencias sociales ha permitido a la demografía hacer interpretaciones de sus variables desde una concepción más multidisciplinaria, en términos de estudios de población y su relación con el desarrollo social y económico.

En este sentido, se concibe la mortalidad como parte de un proceso más general -salud-enfermedad-muerte- y como concreción de los riesgos de muerte definidos como todos aquellos condicionantes socioeconómicos y biológicos que hacen que, en un 
momento determinado, los procesos mórbidos generen una situación de enfermedad tal, que tenga como resultado un deterioro irreparable de la salud o incluso la muerte.

Consecuente con lo anterior se hace necesario superar la visión de población expuesta al riesgo, ya que no se trata de encontrar una tasa o una probabilidad de enfermar o morir, sino de recorrer una red de relaciones de determinación en la cual los procesos mórbidos que configuran un perfil epidemiológico determinan las características particulares de mortalidad de la población. Aquí la mortalidad supera el estatus de variable y es concebida como un recorte conceptual de los riesgos de muerte; mientras este último es un concepto abstracto, no observable, la mortalidad es un resultado particular y observable del proceso salud-enfermedad; es una de las formas materiales que pueden asumir los riesgos de muerte (García, 1992).

$\mathrm{El}$ análisis de mortalidad por causas que presentamos en este trabajo, lo hacemos con esta última perspectiva. Aunque las muertes son el resultado terminal del proceso mencionado y aportan poca información sobre las condiciones de salud-enfermedad de la población, creemos que sí pueden aportar información valiosa acerca de las características que determinaron su desenlace fatal.

Igualmente, el concepto de evitable no tiene un referente empírico directo, no es un concepto operativo como el de "causas prevenibles"; se trata más bien de relacionar el proceso salud-enfermedad-muerte con la potencialidad que tiene la sociedad para transformarlo.

Fuentes de información y análisis de datos

\section{Fuente de datos}

La Dirección General de Estadística de la Secretaría de Salud (DGE-SSA), en común acuerdo con el Instituto Nacional de Estadística, Geografía e Informática (INEGI), sistematiza los registros de defunciones (actas de defunción) como parte de la producción de información del sistema nacional de estadísticas básicas. Aunque esto se viene haciendo desde hace más de $\mathbf{5 0}$ años, apenas desde 1979 se cuenta con bases de datos relativamente confiables y almacenadas en forma electrónica.

La base de datos contiene alrededor de 50000 registros de defunciones por año, y es almacenada en archivos anuales según el año de registro de la defunción, desde 1979 hasta 1991. Para los objetivos de este trabajo se han seleccionado las variables que son comparables en todo el periodo, como son: 
- La causa básica de muerte, desagregada a tres dígitos según la Novena Clasificación Internacional de Enfermedades (CIE), lo que permite la comparabilidad en todo el periodo considerado.

- El municipio y el tamaño de la localidad de residencia habitual del difunto.

- El sexo y la edad.

- La certificación médica.

\section{Calidad y tratamiento de la información}

El análisis de las frecuencias de todas las variables en sus códigos unitarios para los años de 1979 a 1991 no mostró anormalidades de ninguna especie. En lo que se refiere a las causas de defunción, se observó una perfecta correspondencia con la CIE a tres dígitos (novena revisión). Los porcentajes de no certificación médica, de subregistro y de causas mal definidas, están por debajo de los promedios encontrados para México y de los sugeridos como tolerables para hacer estudios de mortalidad por causas (Jaspers y Orellana, 1991; Rodríguez, 1989). Lo anterior sugiere que los archivos anuales de defunciones ofrecen información confiable al menos en lo que concierne a las variables que se usan en el estudio.

Para eliminar fluctuaciones anuales que se deben más al sistema de registro que a cambios reales de la mortalidad, se construyó una serie de defunciones anuales suavizada mediante promedios móviles trienales. Esto quiere decir que un año cualquiera se obtuvo a partir del promedio aritmético de éste y los años adyacentes. Este procedimiento produjo una serie ajustada de registros anuales de defunción entre 1980 y 1990.

Para corregir el subregistro de las defunciones se utilizaron técnicas indirectas que usan información de censos y encuestas, además de los registros de defunción.

Las defunciones de personas mayores de cinco años por sexo y edad fueron evaluadas y ajustadas mediante una técnica que parte de los supuestos de: comportamiento estable de la población, cerrada a la migración y declaración correcta de la edad. El procedimiento consiste en asociar los componentes del crecimiento poblacional, relacionando la población censada por grupos de edad y sexo con el número de defunciones declaradas en un momento dado (Naciones Unidas, 1986; Preston y Coale, 1984: 35-96; Bennett y Horiuchi, 1984: 11-33).

Aunque los supuestos del procedimiento no se cumplen cabalmente, es posible estimar porcentajes mínimos de subregistro teniendo en cuenta el efecto de la migración, que en el caso de la frontera 
norte es significativa. De acuerdo con lo que se conoce de la dinámica demográfica de la región, se compatibilizó la tasa de crecimiento observada con las exigencias de la técnica propuesta por Preston y Coale y las modificaciones realizadas por Arriaga (Naciones Unidas, 1986; U.S. Bureau of the Census, 1992).

Es importante anotar que con estos procedimientos no es posible obtener estimaciones precisas del subregistro dada la calidad de las defunciones en cuanto a la mala declaración de la edad y al no cumplimiento cabal de los supuestos. Sin embargo, es posible evaluar el posible efecto de ese subregistro y hacer correcciones que estén por debajo de los porcentajes reales. De esta manera se pretende respetar la información original y rescatar de ella lo que aportan sus diferenciales. No pretendemos medir con precisión sus niveles.

La mortalidad infantil y juvenil fue estimada a partir de información de los censos de 1980 y 1990 sobre hijos tenidos nacidos vivos e hijos sobrevivientes de las mujeres en edad fértil clasificadas en grupos quinquenales de edad. La idea fundamental del procedimiento consiste en establecer una relación entre la proporción de hijos tenidos nacidos vivos que han fallecido según la edad de la madre y la probabilidad de morir entre el nacimiento y una edad determinada, que también depende de la edad materna.

Aunque los supuestos de fecundidad constante en un periodo reciente y de buena declaración de la edad, entre otros, no se cumplen cabalmente, aquí se utiliza una variante de la técnica original de W. Brass (1974) propuesta por J. Trussel, Familia Oeste (Naciones Unidas, 1986) que entre otras ventajas tiene en cuenta cambios recientes de la mortalidad y refiere las estimaciones $n$ años antes del censo.

Aunque el uso de estas técnicas indirectas han sido criticadas por el no cabal cumplimiento de los supuestos, siguen siendo utilizadas, con las debidas reservas, para evaluar la calidad de las estadísticas vitales, para mostrar la bondad de las mediciones directas e, incluso, se han considerado como estimaciones satisfactorias (García, 1986; Mina, 1988: 284; Gómez de León y Partida, 1993: 101).

A pesar de la evaluación y el suavizamiento de los datos, no se pueden desconocer las limitaciones que tienen estas fuentes de información en términos de mala declaración, registro inadecuado y sesgos administrativos que afectan el sistema estadístico en su conjunto. Por otro lado, las estimaciones indirectas no son más que eso: estimaciones que tratan de corregir algunos problemas de información pero que no pueden ser consideradas como mediciones de los niveles de mortalidad, al menos en este trabajo. Los resultados que aquí se presentan deben ser interpretados teniendo en cuenta este hecho. 
Variables e indicadores utilizados

\section{Estructura de mortalidad}

Para el estudio de la mortalidad por causas se consideró la distribución por sexo y grupos quinquenales de edad para cada uno de los agrupamientos según evitatilidad; se analizaron según su distribución porcentual, número de orden y aporte porcentual y de acuerdo con los años de ganancia en el periodo de la esperanza de vida al nacimiento. Esta distribución se interpretó como la estructura de la mortalidad por causas, permitiendo hacer comparaciones entre subgrupos poblacionales.

\section{Perfil de mortalidad}

Se construyeron a partir de las estructuras de mortalidad definidas anteriormente. Se consideró que estas estructuras asumen comportamientos específicos de acuerdo con los distintos niveles de determinación considerados. Se entiende como perfil de mortalidad de un espacio socioeconómico específico (frontera norte), las características de los riesgos de muerte y que son observables a través de la estructura de mortalidad por causas, género y grupos de edad que lo hacen diferenciable de otros espacios y que son la concreción de procesos de salud-enfermedad-muerte históricamente determinados. El perfil más que un listado de principales causas de muerte, es una síntesis histórica del proceso salud-enfermedad-muerte que expresa, entre otras cosas, las contribuciones a la mortalidad de las condiciones de vida, la política social del Estado y la prestación de servicios de salud.

Los agrupamientos de causas de muerte como variables asociadas a las condiciones socioeconómicas y a la prestación de servicios de salud

Esta relación fue operacionalizada partiendo de las condiciones de evitabilidad. Se reagruparon las causas de muerte según los criterios de muertes evitables y difícilmente evitables; la propuesta de agrupamientos se presenta en el anexo 1 con el nombre según el tipo de evitabilidad y los códigos que corresponden según la CIE, novena revisión. 
Tablas abreviadas de mortalidad para 1980 y 1990

Una vez ajustadas las defunciones se calcularon las tasas de mortalidad por sexo y grupos quinquenales de edad para el total de las cinco entidades federativas, insumo básico para la construcción de las tablas de mortalidad.

Las funciones de la tablas de mortalidad construidas fueron: años.

- Las probabilidades de morir entre las edades exactas $x, X+n$

- Los sobrevivientes a la edad exacta $x$ años.

- Defunciones entre las edades exactas $x, x+n$ años.

- Población estacionaria (años vividos) entre las edades exactas $X, X+n$ años.

- Años por vivir de los sobrevivientes a la edad exacta $x$ años.

- La esperanza de vida a la edad exacta $x$ años.

Estas funciones son calculadas para cada sexo; la esperanza de vida al nacimiento es el número promedio de años que se espera viva un recién nacido si llegara a experimentar las condiciones de mortalidad estimadas para su población. Los procedimientos seguidos en la construcción de las tablas de mortalidad fueron los recomendados de acuerdo con los tipos de datos disponibles (Ortega, 1987). En las tablas de mortalidad anexas para los años 1980 y 1990, se proporcionan algunos detalles tenidos en cuenta durante su construcción, sobre todo en el tratamiento del grupo abierto.

Contribución de los grupos de causas evitables al cambio en la esperanza de vida y al diferencial por sexo.

Procedimiento de Pollard

El razonamiento del procedimiento parte de la afirmación de que una reducción de intensidad en la fuerza de la mortalidad (función que expresa la mortalidad en una edad exacta), en un intervalo pequeño de edades, produce necesariamente un incremento en la esperanza de vida al nacer de la población. Es decir, cada reducción de la mortalidad en una edad individual puede ser calculada teniendo en cuenta el efecto principal y los distintos efectos de interacción sobre la estructura de la mortalidad (Pollard, 1988, 1990; Rodríguez, 1989).

Para ello es necesario disponer de las funciones de la tabla de mortalidad como son los sobrevivientes a una edad exacta y las probabilidades de sobrevivencia en dos momentos en el tiempo. Para medir el efecto de un conjunto de causas se ponderan las probabilidades de muerte de cada grupo de edad por el peso porcen- 
tual de ese grupo de causas; normalmente este tipo de estimaciones se hacen para cada sexo.

Al igual que los procedimientos anteriores, éste no garantiza el cabal cumplimiento de los supuestos, sobre todo aquel que tiene que ver con las interacciones. Pues es posible que una muerte que pudo ser evitada, tenga múltiples opciones de serlo y presentar interacción incluso con las difícilmente evitables. Por otro lado, no se reproducen exactamente las diferencias por sexo, lo que puede ser atribuible a los procedimientos de ponderación y al hecho de que las relaciones exactas sólo se lograrían si se consideran las variables como continuas y no discretas, como se hace para efectos prácticos. En todo caso es posible corregir este tipo de errores (Pollard, 1990: 286).

\section{Procesamiento de datos y análisis estadístico}

Los datos fueron procesados en SPSS/PC+, los promedios móviles trienales fueron procesados electrónicamente y cada distribución numérica y (o) porcentual se refiere al promedio móvil mientras no se diga lo contrario. El análisis estadístico es descriptivo y bivariado. Las estimaciones indirectas de mortalidad, la evaluación de las defunciones y la construcción de las tablas de mortalidad se hicieron con los programas de análisis demográfico para micro-computador: Pass y Pandem.

\section{Resultados}

\section{Evaluación y ajuste de la información}

Para el total del país existen estimaciones en el sentido de que desde 1981 el porcentaje de certificación médica supera $85 \%$, y para el quinquenio 1985-1990 la cobertura del registro de defunciones es de 88 por ciento.

En el cuadro 1 se observan los niveles de certificación médica que, a excepción de Chihuahua, son bastante buenos y cumplen, como ya se había dicho, los mínimos recomendados como para hacer análisis de mortalidad por causas.

Para 1980 se estimó una tasa de mortalidad infantil de 49 por mil y para 1990 de 28 por mil, similares a las encontradas con otros procedimientos por Gómez de León y Partida (1993: 128). Comparadas con las calculadas a partir de estadísticas vitales, se puede decir que éstas están subestimadas en $37 \%$ y $29 \%$, respectivamente. 
CUADRO 1

Frontera norte: porcentaje de certificación médica para menores de 5 años y total, años seleccionados

\begin{tabular}{|c|c|c|c|c|c|c|}
\hline \multirow{3}{*}{ Estado } & \multicolumn{6}{|c|}{ Certificación médica (\%) } \\
\hline & \multicolumn{3}{|c|}{1986} & \multicolumn{3}{|c|}{1990} \\
\hline & 0 & $1-4$ & Total & 0 & $1-4$ & Total \\
\hline Baja California & 99 & 98 & 99 & 99 & 99 & 99 \\
\hline Coahuila & 96 & 93 & 96 & 93 & 95 & 94 \\
\hline Chihuahua & 89 & 72 & 94 & 84 & 72 & 87 \\
\hline Sonora & 98 & 97 & 98 & 99 & 99 & 99 \\
\hline Tamaulipas & 99 & 96 & 98 & 93 & 98 & 96 \\
\hline
\end{tabular}

Para el ajuste de las defunciones de mayores de un año (gráfica 1), parece ser que las tasas de crecimiento seleccionadas presentan una serie invariante de los cocientes de población estimada y población reportada. En estas condiciones, se puede decir que el procedimiento de ajuste propuesto por Preston y Coale puede arrojar resultados razonables (Naciones Unidas, 1986: 142). La diferencia entre las tasas de crecimiento por género puede explicarse por la alta selectividad por género de la migración en la región.

Los factores de ajuste encontrados para hombres (1.03) y para mujeres (1.05) están levemente por debajo de los encontrados para el total del país en la Encuesta Nacional de la Dinámica Demográfica (Enadid) para el periodo 1987-1991 (INEGI, 1994: 72).

Dado los altos niveles de certificación médica y una cobertura de defunciones que se puede definir como "satisfactoria" (Jasper y Orellana, 1991: 7), se optó por no ajustar la distribución de las defunciones por causas observada. Se parte del supuesto de que las defunciones que se dejaron de registrar tienen la misma composición de mortalidad por causas o que, de ser distinta, no modifica sustancialmente la estructura de la mortalidad por causas que se discute en este trabajo.

\section{Diferenciales de mortalidad por causas según evitabilidad}

Como se puede observar en la gráfica 2, las causas de muerte evitables representan alrededor de $50 \%$ del total de muertes en toda la frontera, y el descenso en los diez años es mínimo (6.4 puntos porcentuales).

El porcentaje que aportan se puede ver en las causas mal definidas como un criterio de evaluación de los datos. Éste está por 


\section{GRÁFICA 1}

Análisis gráfico para ajustar las defunciones de mayores de un año. Procedimiento Preston-Coale

Frontera norte: hombres, 1990

Coeficientes $\mathrm{N}^{*} / \mathrm{N}$

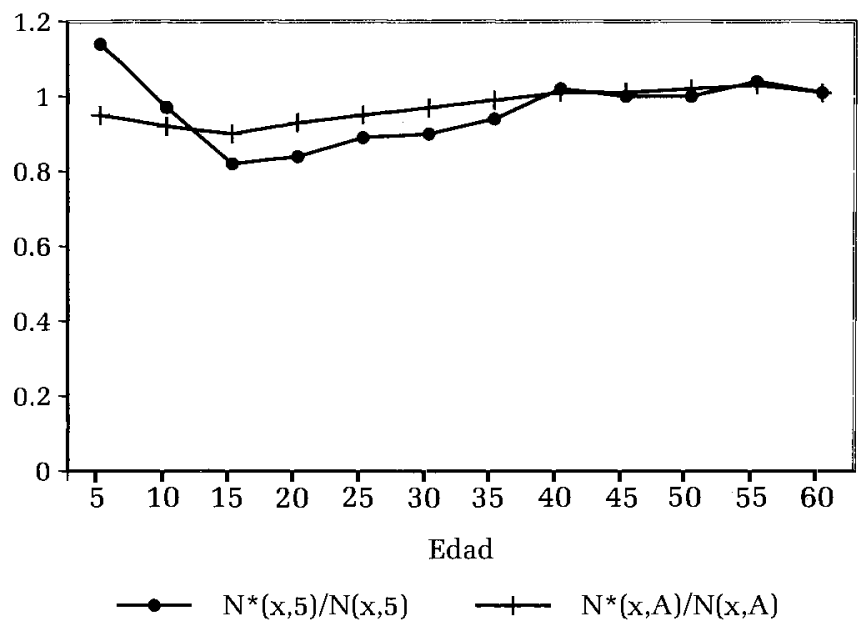

Tasa de crecimiento para mejor ajuste: 2.7 por ciento.

Frontera norte: mujeres, 1990 Coeficientes $\mathrm{N}^{*} / \mathrm{N}$

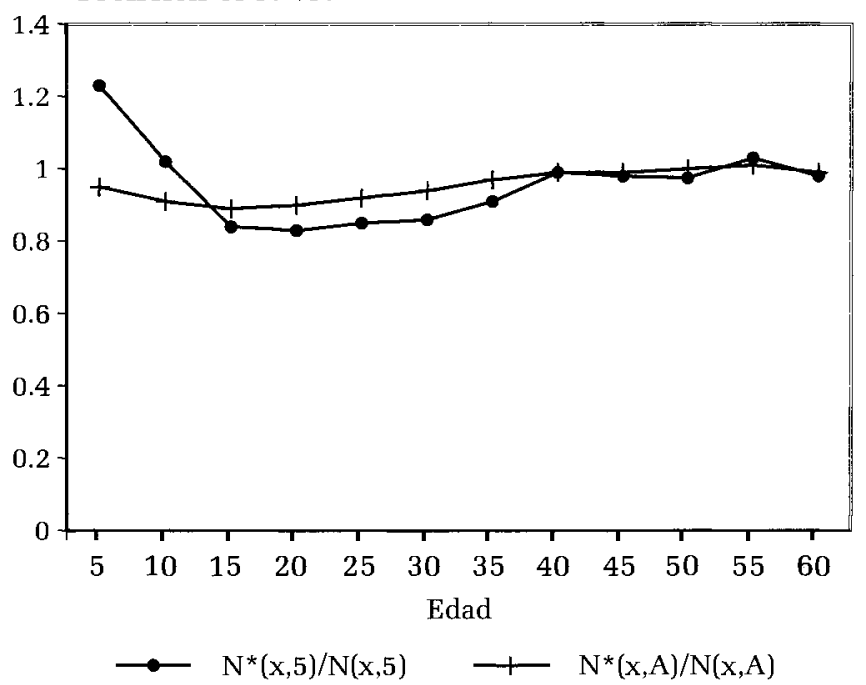

Tasa de crecimiento para mejor ajuste: 3.1 por ciento. 
GRÁFICA 2

Frontera norte: estructura porcentual de defunciones según evitabilidad. 1980-1990

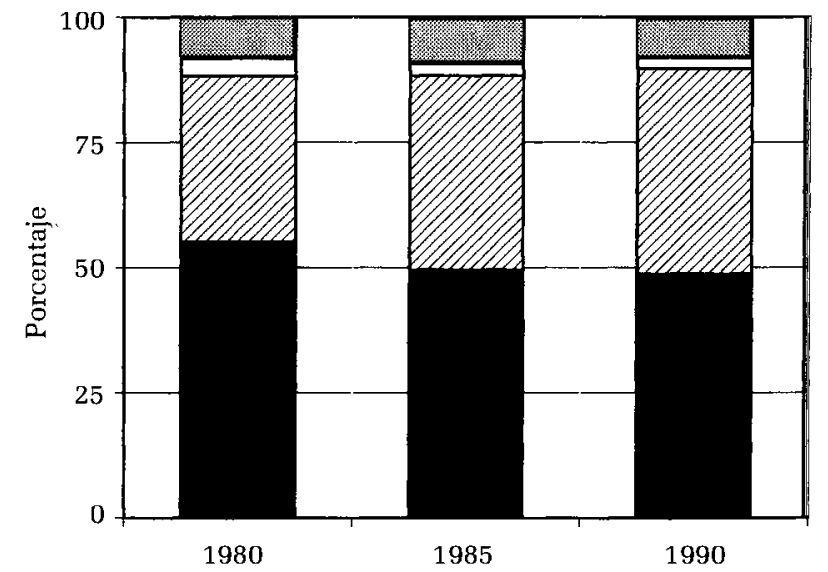

\begin{tabular}{lcrr}
\multicolumn{1}{c}{ Evitables } & Difícil evitar & $\square$ Mal definidas & Otras \\
Evitables & 55.1 & 49.5 & 48.7 \\
Difícil evitar & 33.2 & 38.8 & 41.0 \\
Mal definidas & 3.5 & 2.4 & 2.2 \\
Otras & 8.2 & 9.3 & 8.1
\end{tabular}

Fuente: Bases de mortalidad, INEGI/SSA.

debajo de $4 \%$ y descendió de manera importante en el periodo. El grupo de "otras" podría decirse que ha permanecido estable en la década.

Cuando se compara la estructura porcentual de las causas de muerte según condiciones de evitabilidad en los cinco estados, se perciben pocas diferencias (gráfica 3 ). Al igual que lo observado para el total de la frontera, es mínimo el descenso en el porcentaje de causas evitables. Para 1990 Coahuila presenta el menor porcentaje de muertes evitables (46.2) y Baja California, Chihuahua y Sonora presentan todavía $50 \%$ de defunciones que pudieron haber sido evitadas. Aunque pequeñas, estas diferencias dan cuenta de distintas realidades de salud-enfermedad-muerte en los distintos estados fronterizos. El bajo porcentaje de causas mal definidas en todos los estados, sugiere una buena calidad de la información en cuanto a los diagnósticos de las causas de muerte.

Ahora, considerando el aporte de los distintos subgrupos de muertes evitables con respecto al total de defunciones y por género, se observan diferencias importantes (gráficas 4 y 5 ). 
GRÁFICA 3

Frontera norte: estructura porcentual de defunciones según evitabilidad, 1990

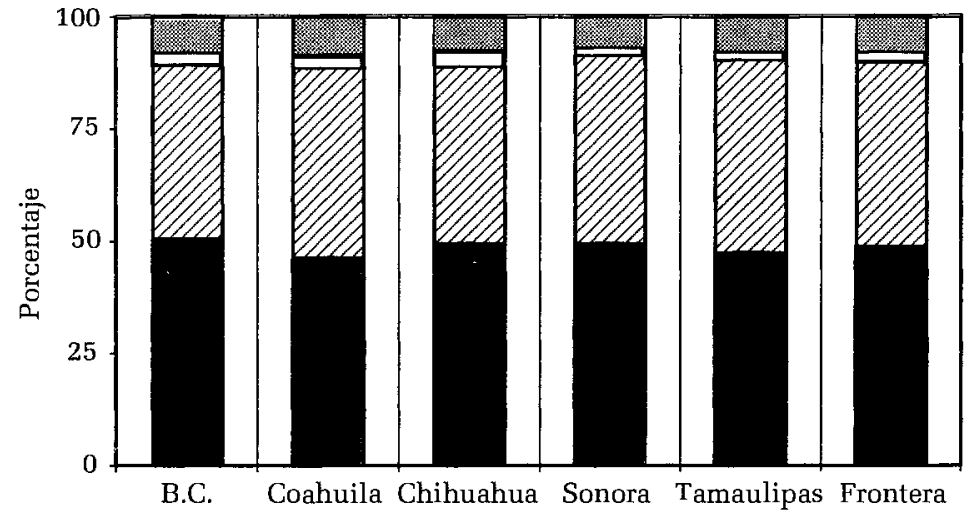

\begin{tabular}{lrrrrrr} 
& Evitables & \multicolumn{3}{c}{ D Difícil evitar } & & \multicolumn{3}{c}{$\square$ Mal definidas } & 2 Otras \\
Evitables & 50.4 & 46.2 & 49.8 & 49.6 & 47.3 & 48.7 \\
Difícil evitar & 38.7 & 42.7 & 39.5 & 41.9 & 43.3 & 41.0 \\
Mal definidas & 2.7 & 2.3 & 3.4 & 1.3 & 1.1 & 2.2 \\
Otras & 8.2 & 8.8 & 7.8 & 7.5 & 8.3 & 8.1
\end{tabular}

Fuente: Bases de mortalidad, INEGI/SSA.

GRÁFICA 4

Frontera norte: estructura porcentual de defunciones evitables en hombres, 1980-1990

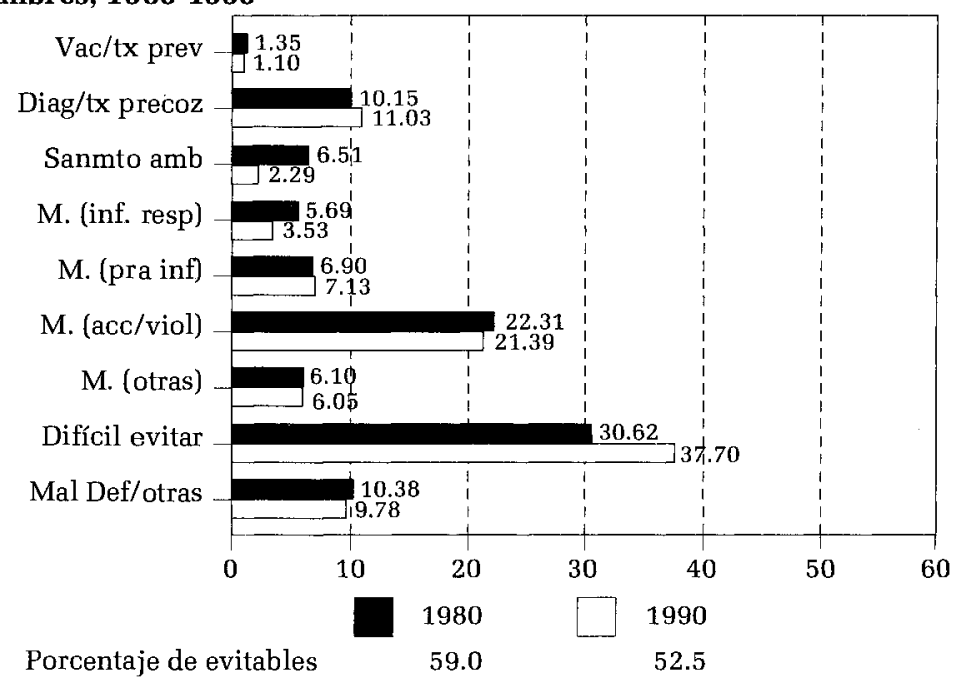

Fuente: Bases de datos, INEGI/SSA. 
GRÁFICA 5

Frontera norte: estructura porcentual de defunciones evitables en mujeres, 1980-1990

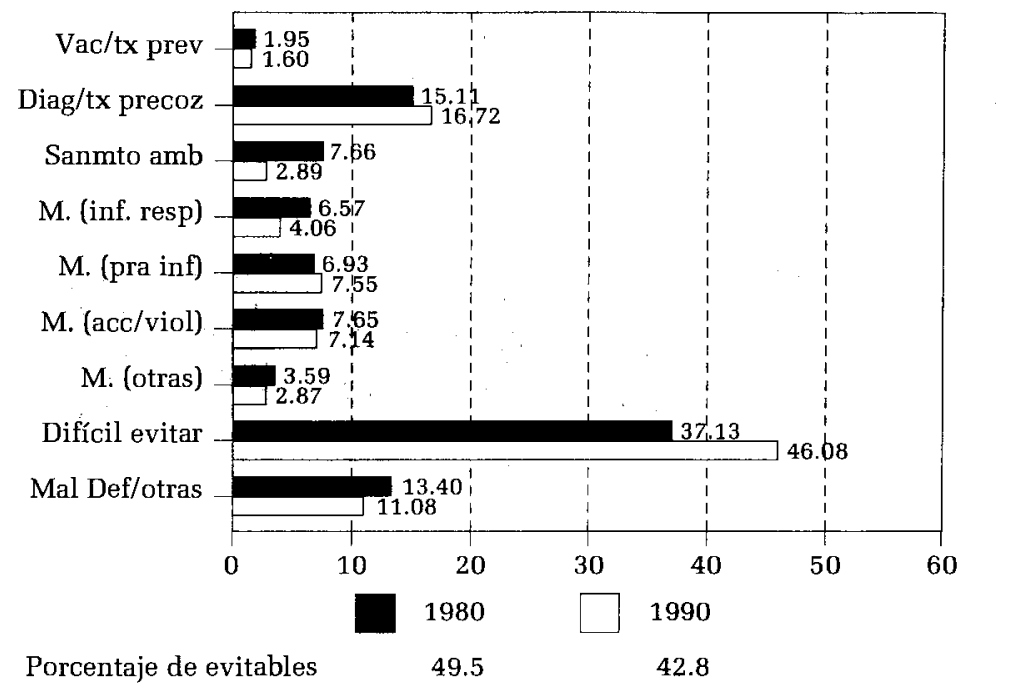

Fuente: Bases de datos, INEGI-SSA.

Las muertes evitables por vacuna y tratamiento preventivo son muy bajas y la reducción obtenida en la década no deja de ser discreta. Sin embargo, han sido famosas las campañas nacionales de vacunación y se consideran relevantes las cifras sobre cuadros completos de inmunización. Las muertes que pudieron haber sido evitadas por diagnósticos médicos y tratamiento precoz supera en los hombres $10 \%$ y en las mujeres $15 \%$. En la década, la tendencia de la importancia relativa de estas causas de muerte fue al aumento. Si se considera que son enfermedades relacionadas con la prestación de servicios de salud y se analiza en qué medida éstos responden a las necesidades y a la demanda de salud de la población, y si se revisan las campañas de detección precoz del cáncer de mama y útero, próstata y de estómago, entonces es posible afirmar que los servicios de salud no han sido racionales en la manera de atender las necesidades de la población, sobre todo de las mujeres.

Las causas evitables con medidas de saneamiento ambiental han tenido un descenso de más de $50 \%$ en la década. Sin embargo, todavía $2.5 \%$ de las muertes se deben a factores de riesgo asociadas a precarias condiciones de vida y sin posibilidades de 
atención médica. Para 1990, Sonora presentaba el mayor porcentaje; esto lo convierte en un estado prioritario en el control de factores de riesgo asociados al ambiente.

Las causas de muerte evitables por un conjunto de medidas mixtas están subdivididas en cuatro subgrupos: infecciosas y respiratorias, cuya importancia relativa descendió en $50 \%$, con una mayor presencia en las mujeres. En conjunto, son las que menos aportan en 1990, pero que todavía representan cerca de $4 \%$ de las muertes totales. Las causas asociadas a la primera infancia han mantenido su aporte en el periodo y representan más de $7 \%$ de la mortalidad total. Baja California presenta el mayor porcentaje, se trata de enfermedades fácilmente controlables con buenos servicios de atención materno-infantil.

Como ya se había advertido anteriormente, son los accidentes y la violencia las causas de muerte evitables que mayor porcentaje representan en el total de muertes. Es el género masculino el que más muertes aporta (21.4 \% en 1990), tres veces más que sus congéneres. La disminución de su importancia relativa en el periodo ha sido mínima y las diferencias entre estados no son despreciables y tienden a ahondarse. En Baja California, en 1980, una de cada cinco muertes se debió a causas definidas como accidentes o violencia; para 1990 dicha relación descendió pero no lo hizo de manera importante. Más preocupante es el caso de Chihuahua, donde la importancia relativa de dichas causas se incrementó en el periodo, pues su porcentaje pasó de 16 a $18 \%$, siendo junto con Baja California los estados que más aportan por este tipo de causas.

El cuarto subgrupo es residual y comprende enfermedades como la tuberculosis, las asociadas al embarazo, parto y puerperio y la cirrosis hepática. Su estabilidad en el tiempo y su aporte al total de muertes (más de $4 \%$ ), cuestionan seriamente la efectividad de la medicina preventiva en la región y de los programas de salud específicos, dirigidos a disminuir factores de riesgos de dichas enfermedades.

\section{Contribución de las causas evitables a la esperanza de vida}

Como ya se había advertido en la metodología, las estimaciones que aquí se presentan de la esperanza de vida al nacimiento serán utilizadas para mostrar diferencias; el nivel de la medición depende mucho del cumplimiento de los supuestos de las técnicas de evaluación y ajuste utilizadas. Es posible que las esperanzas de vida estén un poco por encima de su valor real (sobreestimadas). 
Las gráficas 6 y 7 y el anexo 3 (tablas de mortalidad para la región en los años 1980 y 1990) muestran, para la década, un panorama general de la mortalidad y de la esperanza de vida por género y por grupos de edad. Una ganancia promedio de 4.1 años en la esperanza de vida para una década es discreta si se parte del hecho de que cerca de $50 \%$ de las causas pueden ser evitables y de que en países de alta mortalidad y en procesos de disminución importantes, logran un promedio de .5 años de ganancia anual.

La diferencia en la esperanza de vida al nacimiento entre géneros ha disminuido en .4 años y, aunque pequeña, es muy significativa esa disminución pues lo normal, lo que tradicionalmente se ha venido midiendo y observando, es una sobremortalidad en aumento y principalmente debido a una mayor mortalidad masculina por causas registradas como accidentes y violencia. Pero como ya se dijo anteriormente, una mayor disminución en favor del género masculino ha hecho posible que la tendencia empiece a modificarse.

\section{GRÁFICA 6}

Frontera norte: esperanza de vida al nacimiento según género, 1980-1990

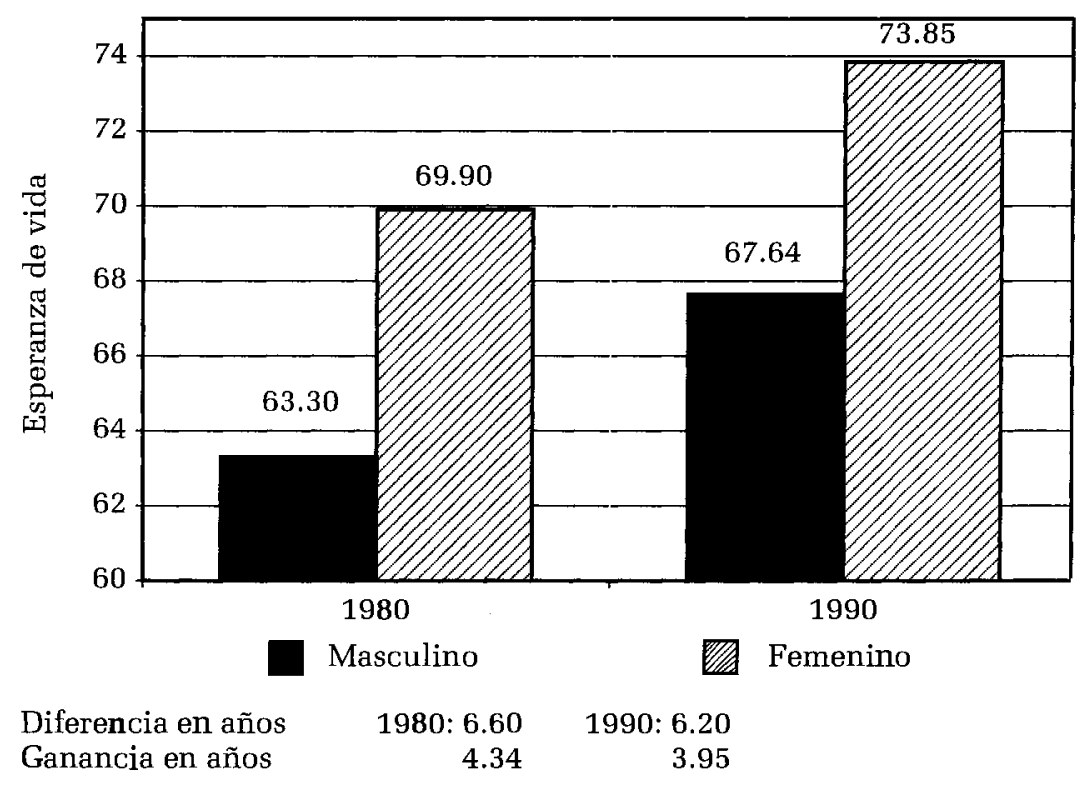

Fuente: Bases de datos, INEGI/SSA. 
GRÁFICA 7

Probabilidades de muerte ajustadas según género y grupos de edad, 1980-1990

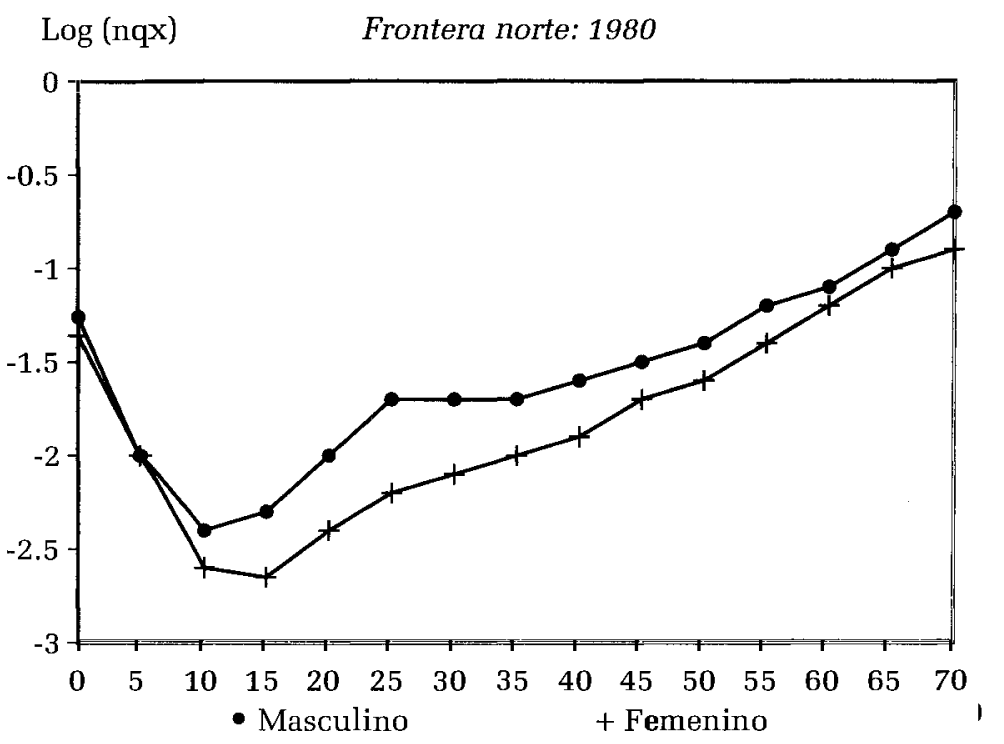

Fuente: Anexo 3.

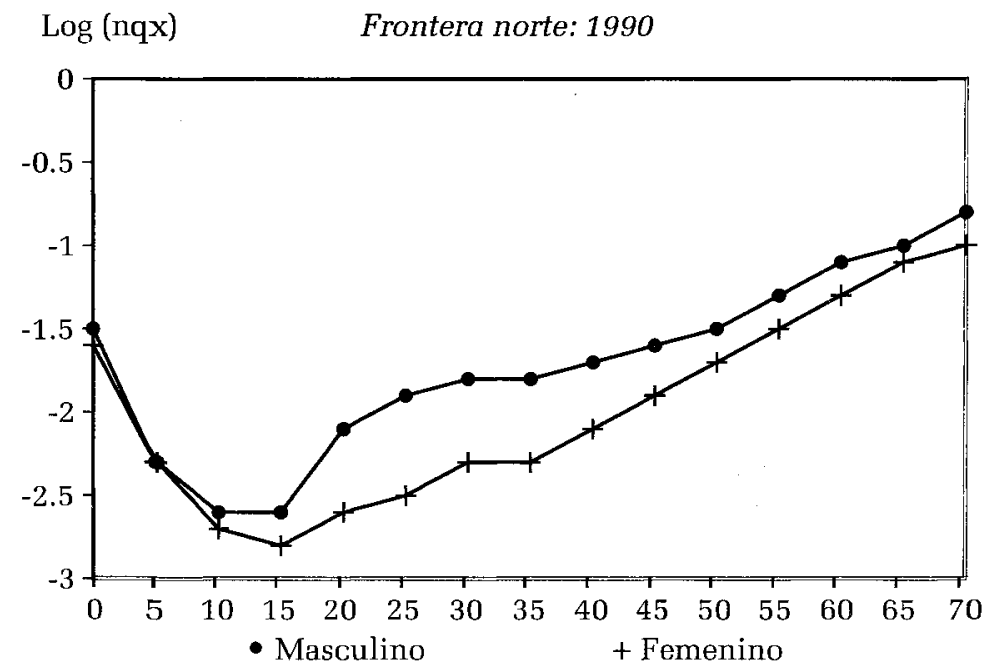

Fuente: Anexo 3. 
En efecto, mientras en la década de los ochenta la ganancia masculina en la esperanza de vida ascendió a 4.3 años, sus congéneres obtuvieron 3.95 años, lo que explica la disminución de la diferencia por género.

Los patrones de mortalidad por género y grupos de edad se han modificado poco (véase la gráfica 7). Esto sugiere que aunque ha habido cambios importantes en la estructura de la mortalidad por causas, éstos no han modificado de manera sustancial los patrones de mortalidad en la región.

Las ganancias en la esperanza de vida fueron descompuestas según el aporte de cada grupo de causas evitables y grupos de edad. La gráfica 8 es concluyente en el sentido de que todavía las ganancias en la sobrevivencia se vienen obteniendo por el descenso de la mortalidad infantil (más de $35 \%$ de aporte a la ganancia en la esperanza de vida).

Como es obvio, son las muertes infantiles evitadas las que mayor impacto tienen sobre la esperanza de vida, pero lo que está muy lejos de la obviedad es el hecho de que el componente principal de la disminución de la mortalidad dependa de los infantes, cuando la mortalidad adulta en México es todavía alta si se le compara con otros países. La población de 50 años y más ha logrado contribuir a dicha ganancia con poco más de $20 \%$; el aporte femenino ha sido mayor y muy parecido a lo observado para el total del país en la década de los setenta.

Aunque importante, se considera que el aporte a las ganancias, de la población entre 15 y 49 años es insuficiente, si realmente se busca obtener perfiles de mortalidad que se correspondan con aquellos países y (o) regiones que se caracterizan por una baja mortalidad (véase la gráfica 8 ).

Como se observa en la gráfica 9 , el mayor aporte a la ganancia en la esperanza de vida masculina se concentra en los grupos evitables: accidentes y violencia, saneamiento ambiental e infecciones respiratorias, en su orden. El aporte femenino lo hacen las de saneamiento ambiental, infecciosas respiratorias y diagnóstico y tratamiento médico precoz. Estas diferencias se pueden entender como un efecto directo de los distintos perfiles de mortalidad.

Si se comparan estos resultados con las gráficas 4 y 5 , que contienen las estructuras de la mortalidad por causas según evitabilidad, no sólo se encuentra una asociación directa entre la evolución de la estructura y las ganancias en la esperanza de vida al nacimiento sino que también permite deducir que: si se quiere reducir significativamente la mortalidad en el corto plazo, las acciones en salud tienen que estar dirigidas a incrementar el diagnóstico y el tratamiento médico precoz (adaptación racional del sistema de salud), 
GRÁFICA 8

Distribución porcentual de las ganancias en la esperanza de vida según género y edad

Edad

Frontera norte: $1980-1990$

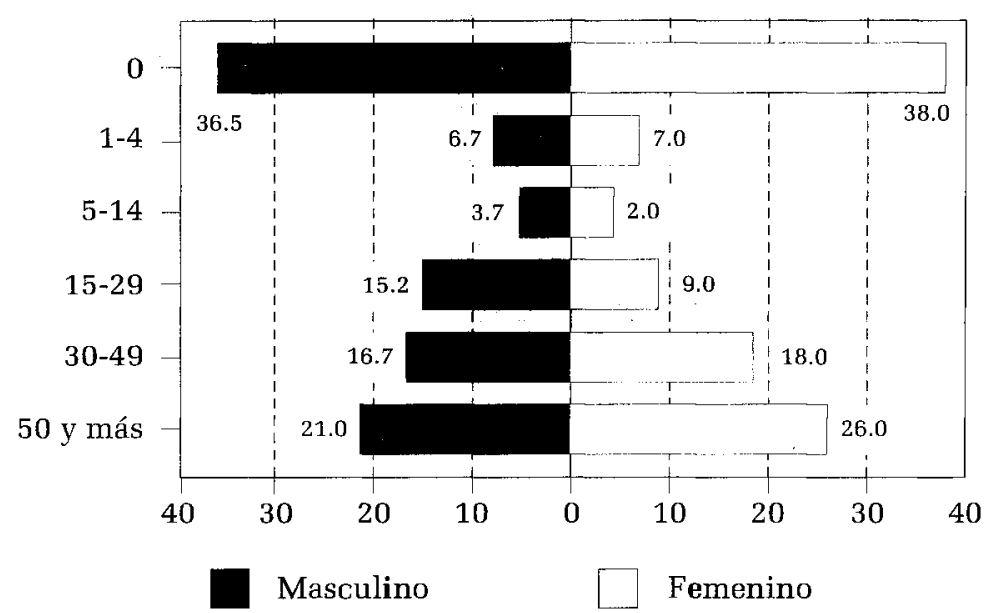

Ganancia en años

4.30

3.95

Fuente: Bases de datos, INEGL/SSA.

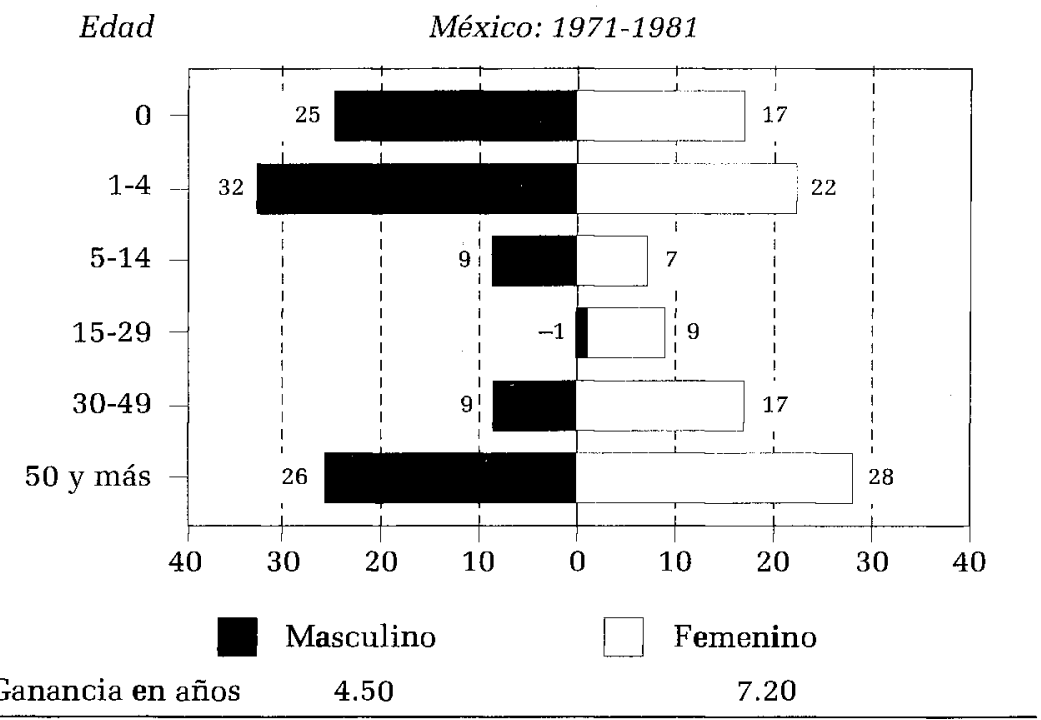

Fuente: Rodríguez, op. cit. 
- Edad Inglaterra: 1971-1981

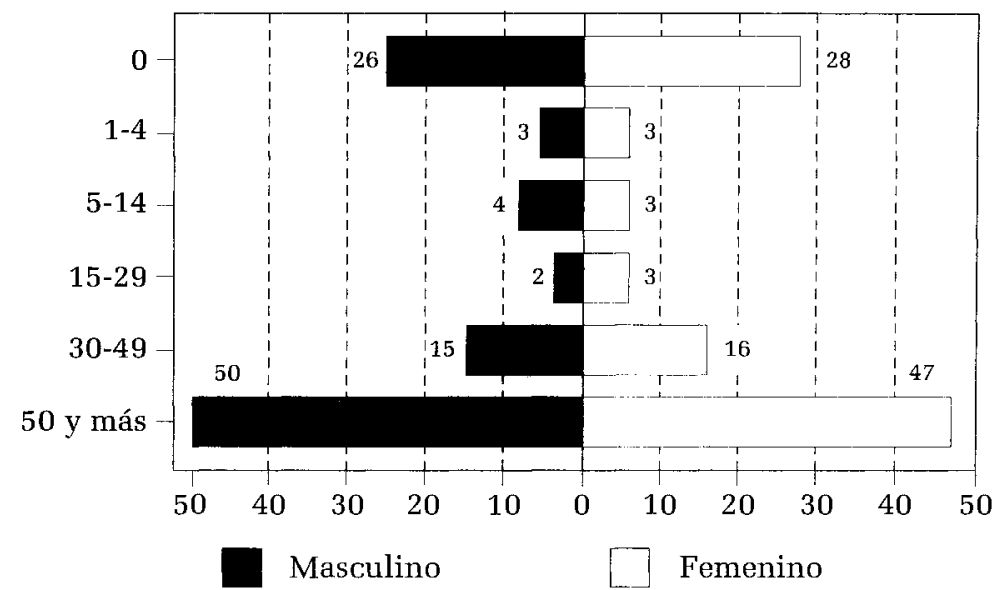

Ganancia en años 1.80 1.50

Fuente: Pollard, op. cit.

GRÁFICA 9

Frontera norte: contribución en años a la esperanza de vida de cada grupo de causas y género, 1980-1990

Causas evitables

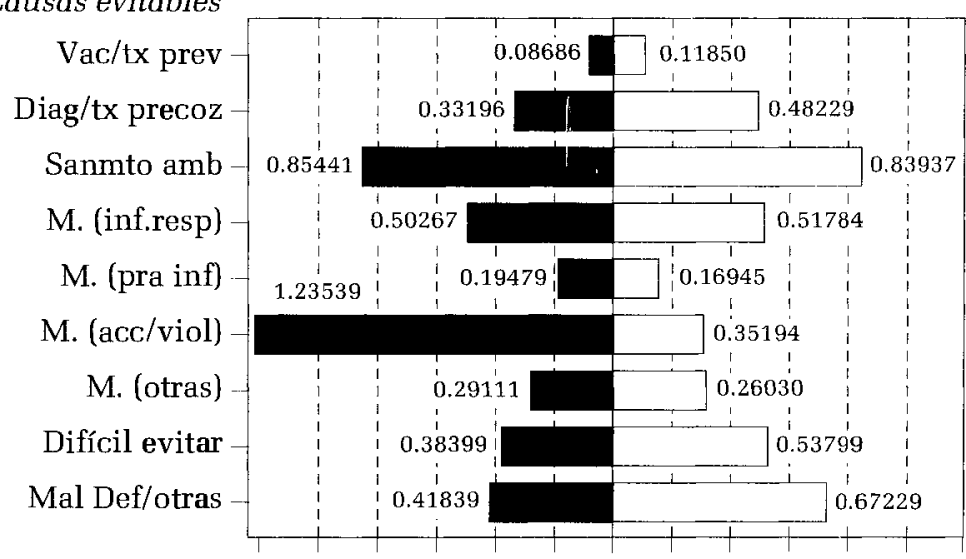

$\begin{array}{lllllllllllll}1.2 & 1.0 & 0.8 & 0.6 & 0.4 & 0.2 & 0 & 0.2 & 0.4 & 0.6 & 0.8 & 1.0 & 1.2\end{array}$

Masculino

Femenino

Ganancia en años

4.30 3.95

Fuente: Bases de datos, INEGI/SSA. 
y la política económica y social a disminuir los factores que producen y reproducen la violencia social, responsable en un alto porcentaje de las muertes causadas por "accidentes, violencia y traumatismos". Más de 50\% de la ganancia en la esperanza de vida masculina se debe a pequeños descensos en la importancia relativa de causas asociadas al medio ambiente, accidentes y violencias.

En síntesis y como lo sugiere la gráfica 9, el perfil de mortalidad de la frontera norte dista mucho de acercarse a nuevos perfiles caracterizados por su asociación con los hábitos de vida y el aprovechamiento constante de las tecnologías médicas; más bien depende todavía de causas de muerte evitables con una mejor irradiación de los beneficios del desarrollo y con servicios de salud que efectivamente se correspondan con las necesidades de la población.

\section{Discusión y conclusiones}

Si bien las diferencias encontradas se pueden asociar con las características socioeconómicas de los estados y de las condiciones particulares que asume la frontera en su proceso de internacionalización, ello no se puede hacer de manera mecánica. No es posible atribuirle una relación de causa-efecto; aunque sí tiene mucho que ver el nivel de desarrollo, hay que incluir variables políticas como la respuesta del sistema de salud a las demandas y necesidades de la población y la forma como ésta concibe y opta por un marco de opciones en salud de acuerdo con sus particulares condiciones socioeconómicas (García, 1992; Arredondo et al., 1992).

Es preocupante el alto porcentaje de accidentes y violencia encontrado en algunos estados o ciudades de la frontera; el lugar donde se registran este tipo de acontecimientos es la vía pública y normalmente se trata de fuerza de trabajo masculina. El hecho de que la fuerza de trabajo esté muriendo en la calle no tiene justificación plausible desde las teorías de la modernización, mucho menos desde el punto de vista de la acumulación de capital. Esta situación debe ser analizada con más detalle por los estudiosos de la mortalidad al interior de cada entidad federativa y según los distintos sectores de la economía.

La modernización no nos está matando de ataques al miocardio, sino de la violencia que produce el mismo desarrollo y de enfermedades altamente diferenciables por género y ocupación, lo que evidencia una forma desigual de contribuir al desarrollo y de apropiarse del bienestar social que éste produce. Teorías acerca de la "transición epidemiológica" y la "transición demográfica" están 
todavía insuficientemente desarrolladas como para dar explicaciones a este tipo de fenómenos (Possas, 1993; Patarra, 1993).

Si en una década no se logró disminuir de manera importante aquellas causas que realmente tienen posibilidades de hacerlo, es difícil pensar que en el corto plazo pueda llevarse a cabo. Aunque los procesos de salud-enfermedad-muerte son de larga duración y las tendencias deben ser analizadas en periodos lo más largo posibles, creemos que estos resultados nos están mostrando al menos dos cosas importantes: la primera es que algo pasa en el sistema de salud y en el acceso de la población a los beneficios del desarrollo, que no hacen posible la disminución de las causas evitables y, en segundo lugar, no es posible hablar de cambios de perfiles de mortalidad, si tanto la estructura como el descenso de la mortalidad siguen dependiendo de causas que pudieron haber sido evitadas.

Por otro lado, no se puede decir que se está en un régimen de baja mortalidad, ya que las ganancias en la esperanza de vida por género, edad y condición de evitabilidad se corresponden con perfiles de alta mortalidad. Los descensos de mortalidad se consiguen en la población infantil y juvenil, situación observada a nivel nacional (Rodríguez, 1989: 77), y todavía se está muy lejos de lograr bajas mortalidades. La mayor contribución a las ganancias en la esperanza de vida se logran en la población mayor de 50 años, como está ocurriendo en algunos países europeos (Pollard, 1990: 283). Cuando se compara la mortalidad de México con la de otros países de América Latina, nuestro país se ubica en una situación intermedia (Arriaga, 1993).

Al contrario de la creencia popular, y como lo reporta Pollard para algunos países europeos (1990: 272-280), la disminución relativa de los accidentes y la violencia no sólo ha contribuido con importantes incrementos en la esperanza de vida sino que ha logrado disminuir, levemente, la brecha de la mortalidad entre géneros.

En todo caso, el hecho de que hoy la población masculina presente condiciones de mortalidad en las que alrededor de $50 \%$ de las defunciones pudieron haber sido evitadas, y de que sus congéneres apenas hayan pasado levemente esta barrera, debe ser considerado como un rasgo característico del perfil de la mortalidad en la frontera norte; es una realidad que debe preocupar al sector salud y a cualquier persona que pretenda mejorar las condiciones de salud de su población. 


\section{Bibliografía}

Arredondo, Armando, Xóchitl Castañeda, Carlos García, Jorge Escobedo y Catalina Ramírez (1992), "El enfoque de las ciencias sociales para el análisis de la morbi-mortalidad: reflexiones para su enseñanza", en Revista Mexicana de Educación Médica, vol. 3, núm. 2, pp. 16-29.

Arriaga E., Eduardo (1993), "La transición de la mortalidad en cuatro países de América Latina", en IV Conferencia Latinoamericana de Población, 23 al 26 de marzo de 1993, México, ABEP/Celade/IUSSP/Prolap/Somede, vol. 2, pp. 139-184.

Bennett, Neil y Shiro Horiuchi (1984), "Estimación del grado de cabalidad en el registro de las muertes en una población cerrada", en $\mathrm{No}$ tas de Población, San José, año XII, núm. 35, pp. 11-33.

Brass, W. (1974), Métodos para estimar la fecundidad y la mortalidad en poblaciones con datos limitados, Santiago (Chile), Celade, Serie E, núm. 14.

García M., Carlos (1986), Mortalidad infantil y clases sociales. El caso de Medellín en la década de los 70 , Medellín, Universidad Pontificia Bolivariana.

- (1992), La desigualdad social ante la salud y la muerte: el caso de Medellín-Colombia. Una visión histórica, tesis de doctorado, México, El Colegio de México.

- María V. López L. y Juan Rodríguez M. (1994), "Frontera norte: perfiles de mortalidad en la década de los ochenta. Una interpretación socio-demográfica", en Revista Sociotam, Ciudad Victoria (Tamaulipas), vol. 4, núm. 1, pp. 85-101.

Gómez de León C., José y Virgilio Partida B. (1993), "Niveles de mortalidad infantil y fecundidad en México, por entidad federativa, 1990", en Revista Mexicana de Sociología, año LV, núm. 1, pp. 97-135.

INEGI (1994), Encuesta nacional de la dinámica demográfica. Análisis de resultados, Aguascalientes.

Jaspers, Dirk y H. Orellana (1991), "Evaluación del uso de estadísticas vitales para el estudio de la mortalidad por causas en América Latina", en Seminar on Causes and Prevention of Adult Mortality in Developing Countries, Santiago (Chile), Celade.

López L., María Victoria (1991), Perfiles de morbilidad en las regiones de Antioquia, Colombia durante los años ochenta, tesis de maestría en Medicina Social, México, UAM-Xochimilco.

Mina V., Alejandro (1988), "La medición indirecta de la mortalidad infantil y en los primeros años de vida en México", en Mario Brofman y José Gómez de León (coords.), La mortalidad en México, México, El Colegio de México.

Naciones Unidas (1986), Técnicas indirectas de estimación demográfica, Washington D.C. (Manual X).

Negrete Mata, José (1990), "La frontera norte de México en los informes presidenciales", en Frontera Norte, vol. 2, núm. 3, pp. 169-184. 
Organización Mundial de la Salud (1978), Clasificación Internacional de Enfermedades (CIE), novena revisión, Washington D.C.

Ortega, Antonio (1987), Tablas de mortalidad, San José, Centro Latinoamericano de Demografía (Celade).

Patarra L., Neide (1993), "Transição demográfica: Novas evidencias, velhos desafios", plenaria IV, en IV Conferencia Latinoamericana de Población, 23 al 26 de marzo de 1993, México, ABEP/Celade/Iussp/Prolap/Somede, vol. 1, pp. 151-166.

Pollard, John (1988), "On the Decomposition of Changes in Expectation of Life and Differentials in Life Expectancy", en Demography, vol. 25, núm. 2, pp. 265-276.

- (1990), "Cause of Death and Expectation of Life: Some International Comparisons", en Jacques Vallin, Stand D'Souza y Alberto Palloni (comps.), Measurement and Analysis of Mortality. New Approaches, Oxford, Claredon Press, pp. 268-291.

Possas, Cristina de A. (1993), "A dimensão saúde da transição demográfica: Uma discussão conceitual", en IV Conferencia Latinoamericana de Población, 23 al 26 de marzo de 1993, México, ABEP/Celade/ IUSSP/Prolap/Somede, vol. 2, pp. 97-115.

Preston, Samuel y Ansley Coale (1984), "Estructura por edades, crecimiento, salidas y entradas: una nueva sintesis", en Notas de Población, San José, año XII, núm. 35, pp. 35-96.

Rodríguez, Leticia (1989), México: contribución de las causas de muerte al cambio en la esperanza de vida, 1970-1982, Santiago (Chile), Celade, Serie B, núm. 56.

Taucher, Erica (1978), Mortalidad infantil en Chile: tendencias, diferenciales y causas, Santiago (Chile), Celade, octubre.

(1980), Chile: mortalidad desde 1955 a 1975. Tendencias y causas, Santiago (Chile), Celade, Serie A, núm. 162.

U. S. Bureau of the Census (1992), Populations Analysis Spreadsheets, Washington D.C., Center for International Research.

\section{ANEXO 1}

Propuesta de agrupación

Grupos de causas de muerte según enfermedades y códigos de la lista de clasificación internacional de enfermedades (9a. rev.)

Grupos de enfermedades

Códigos

E1-Defunciones evitables por vacunación o tratamiento preventivo

- Tosferina

- Tétanos

- Otras enfermedades bacterianas

- Sarampión

020-032, 038, 034, 035

- Otras enfermedades virales

- Enfermedades venéreas

$045,050,056,071$

- Fiebre reumática

- Enfermedades reumáticas crónicas del corazón 
ฐ2-Defumciones evitables por diagnóstico y tratamiento módico precoz

- Tumor maligno de mama, del útero y próstata $174,180,185$

- Tumor maligno de otras partes del útero y de las no especificadas

- Úlcera de estómago, duodeno, gastritis y duodenitis

- Apendicitis

- Obstrucción intestinal y hernia

$540-543$

- Otras enfermedades del aparato digestivo

33-Defunciones evitables por saneamiento ambiental

- Fiebre tifoidea

- Otras enfermedades infecciosas intestinales

$001,004,009$

- Todas las demás enfermedades infecciosas y parasitarias 080-083, 085, 086, 100-139, 4-Defunciones evitables por medidas mixtas

Vi1. Infecciones de vías respiratorias

M2. Perinatales y de la infancia

M3. Tuberculosis Complicaciones del embarazo, parto y puerperio $003,005,006,008,070$ Cirrosis hepática

M4. Accidentes, envenenamientos y violencia

I5-defunciones difícilmente evitables

- Tumores malignos (excepto grupo b)

- Esclerosis múltiple y epilepsia

$800-999,304,305$

- Enfermedades cerebrovasculares

- Arterioesclerosis y degenerativas de corazón

- Malformaciones congénitas

- Leucemia y aleucemia

- Linfosarcoma y otros tumores del sistema linfático y hematopoyético

$140-149,150,151,153,154$,

$155,161,162,188,190-199$ 340,345 $430-438$

$410-416,420-429$

$740,745-747$ 204-208

- Espina bífida y meningocele

156-165, 170-173, 175, 181, 183 184, 186-189, 190-208, 250, $440,332,741,742$

I6-Defunciones por causas mal definidas

- Síntomas, senilidad y estados mal definidos $\quad 780,785-789,797-799$

Z7-Otras causas

- Todas las demás enfermedades y códigos no incluidos en los grupos anteriores 


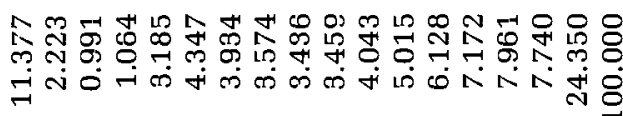

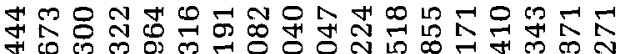

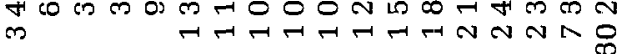

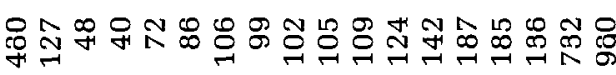

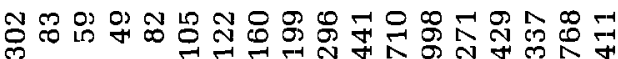
$\rightarrow \rightarrow \infty$

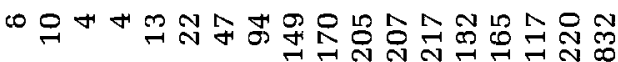

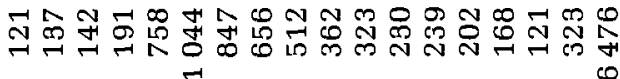
药监

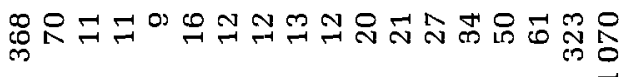

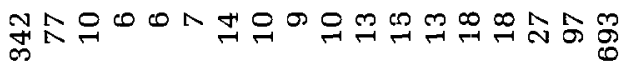

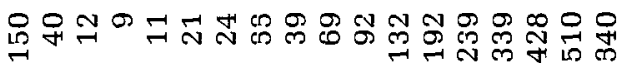

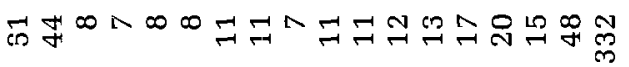

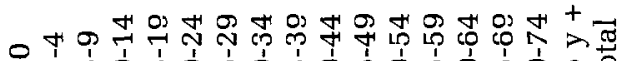

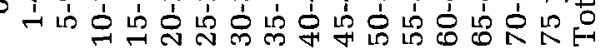




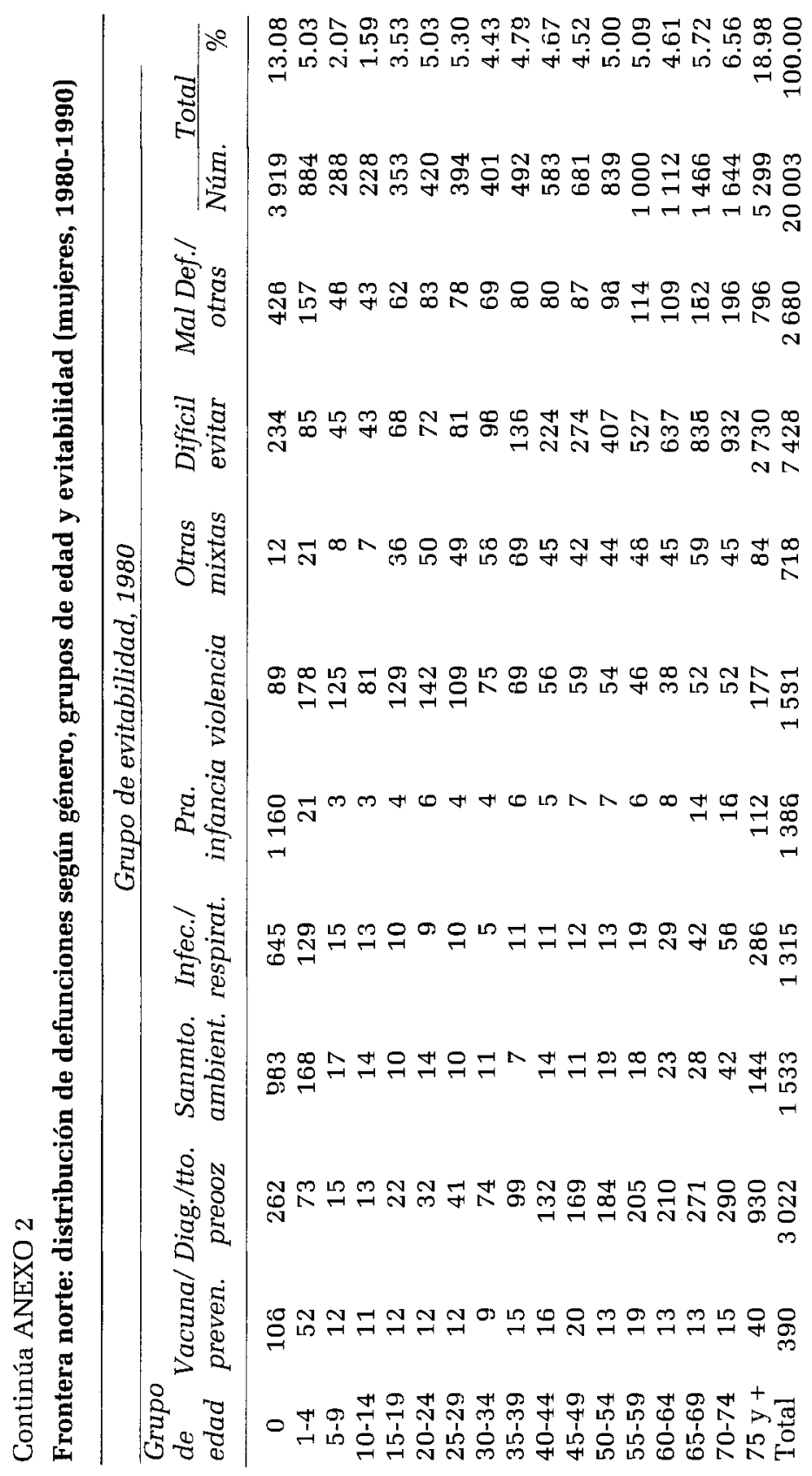


শ্য 出

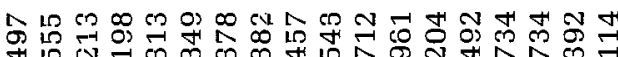
ov 

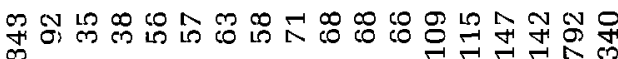

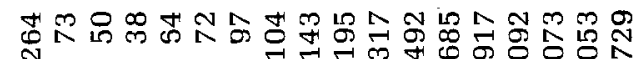
$4 \rightarrow+0$

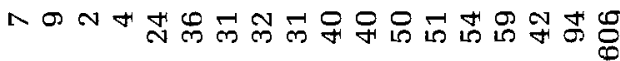

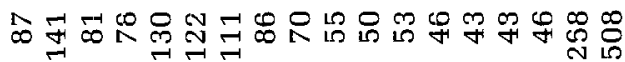
央年 丞

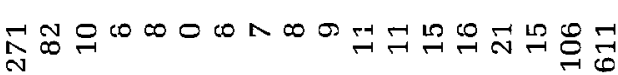
ન న

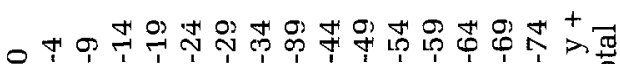




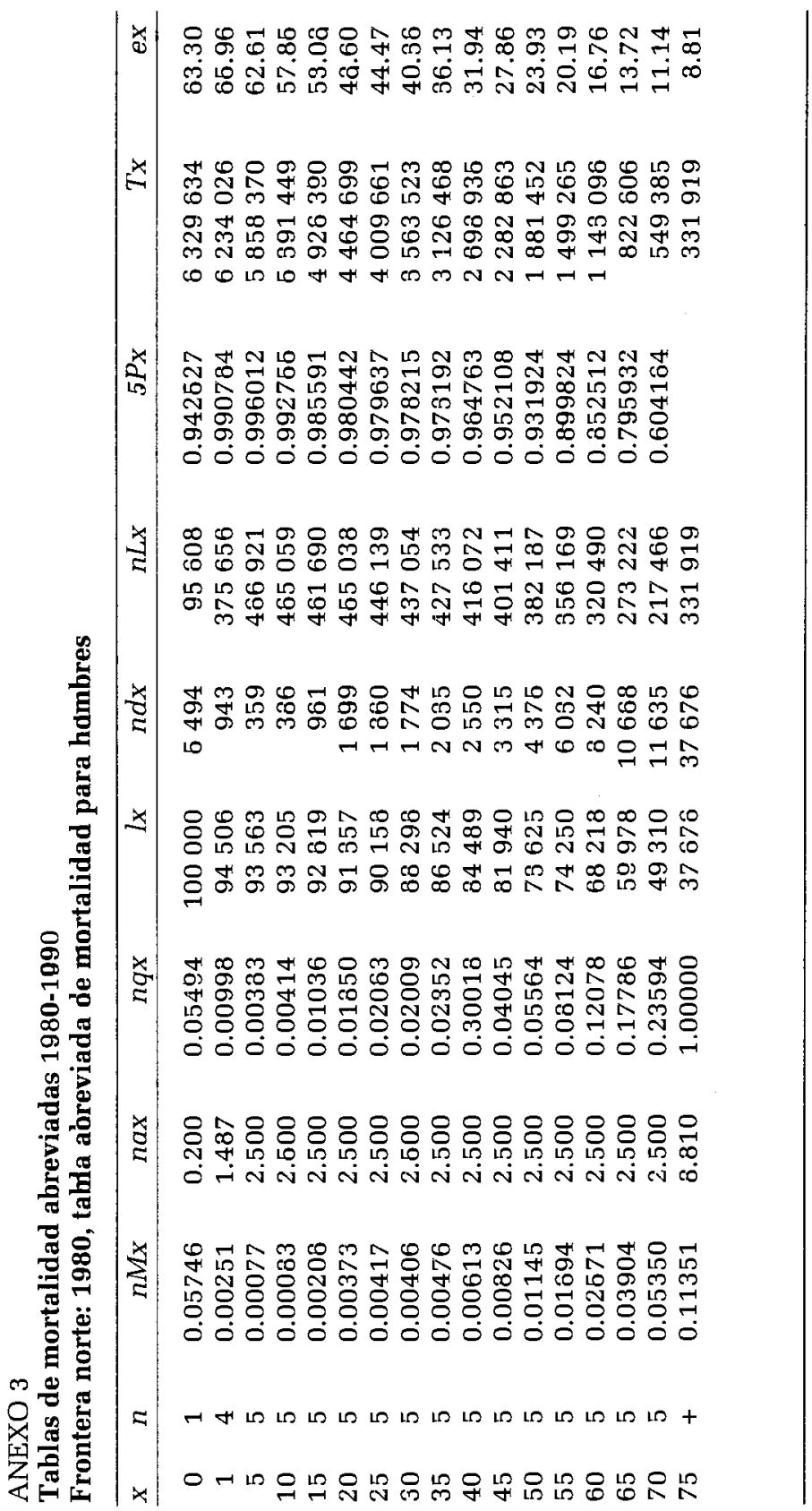




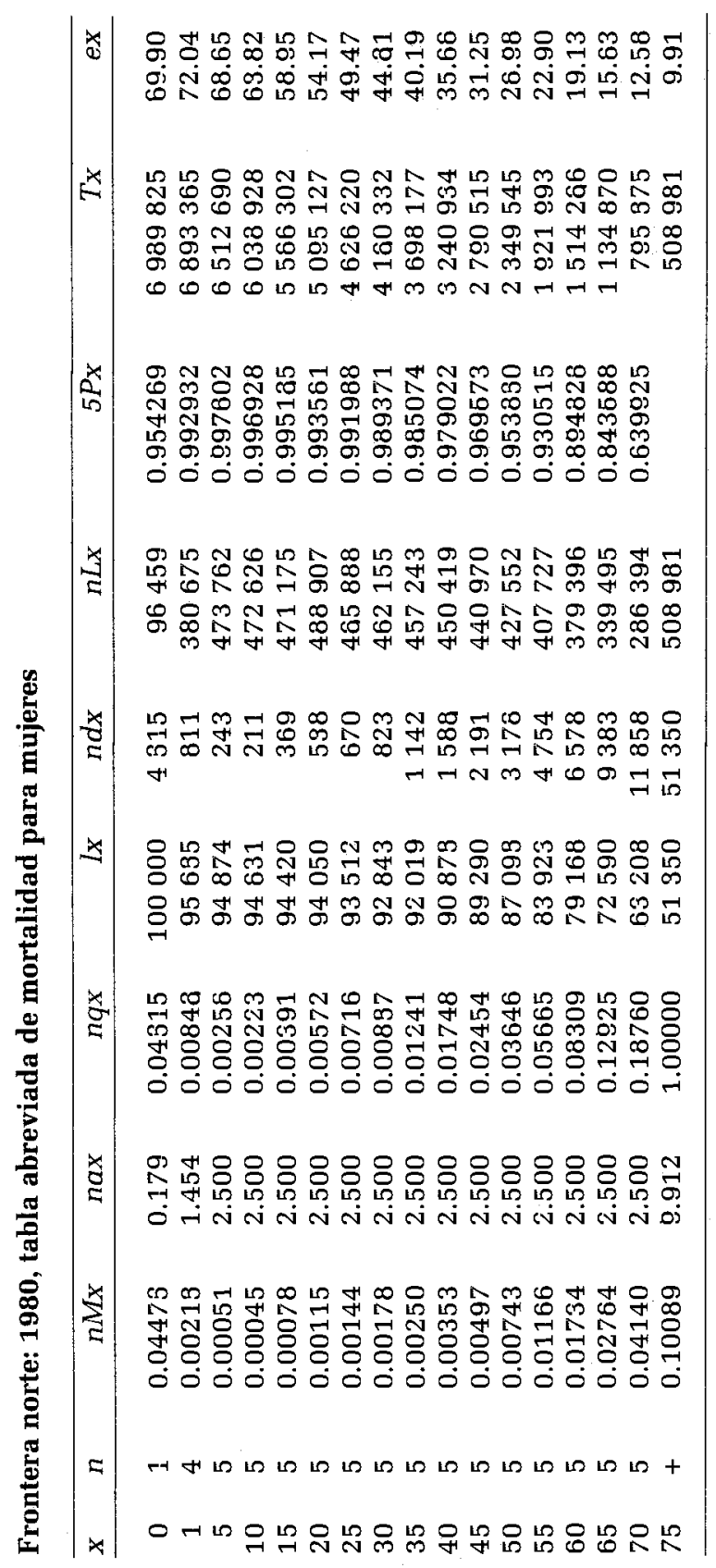




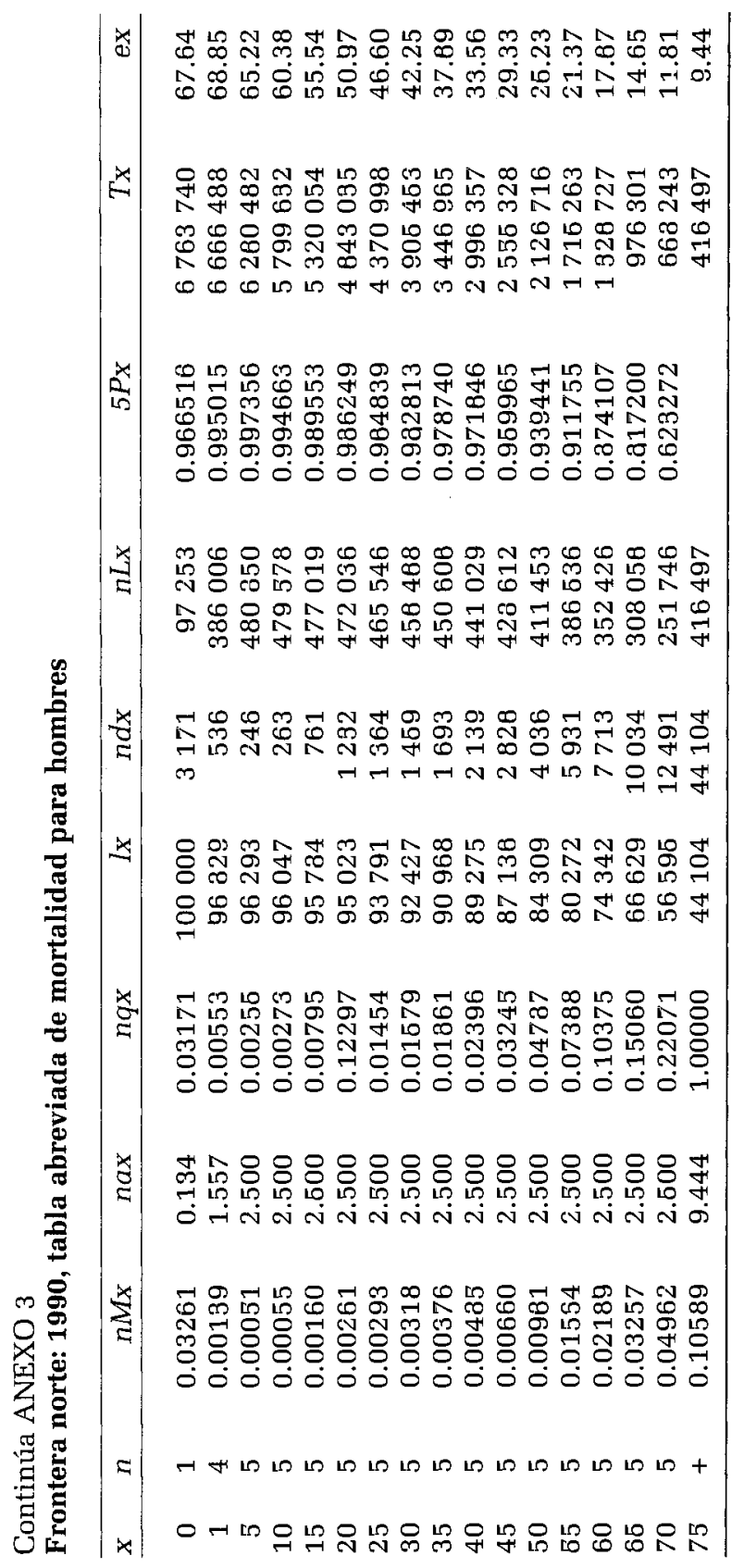




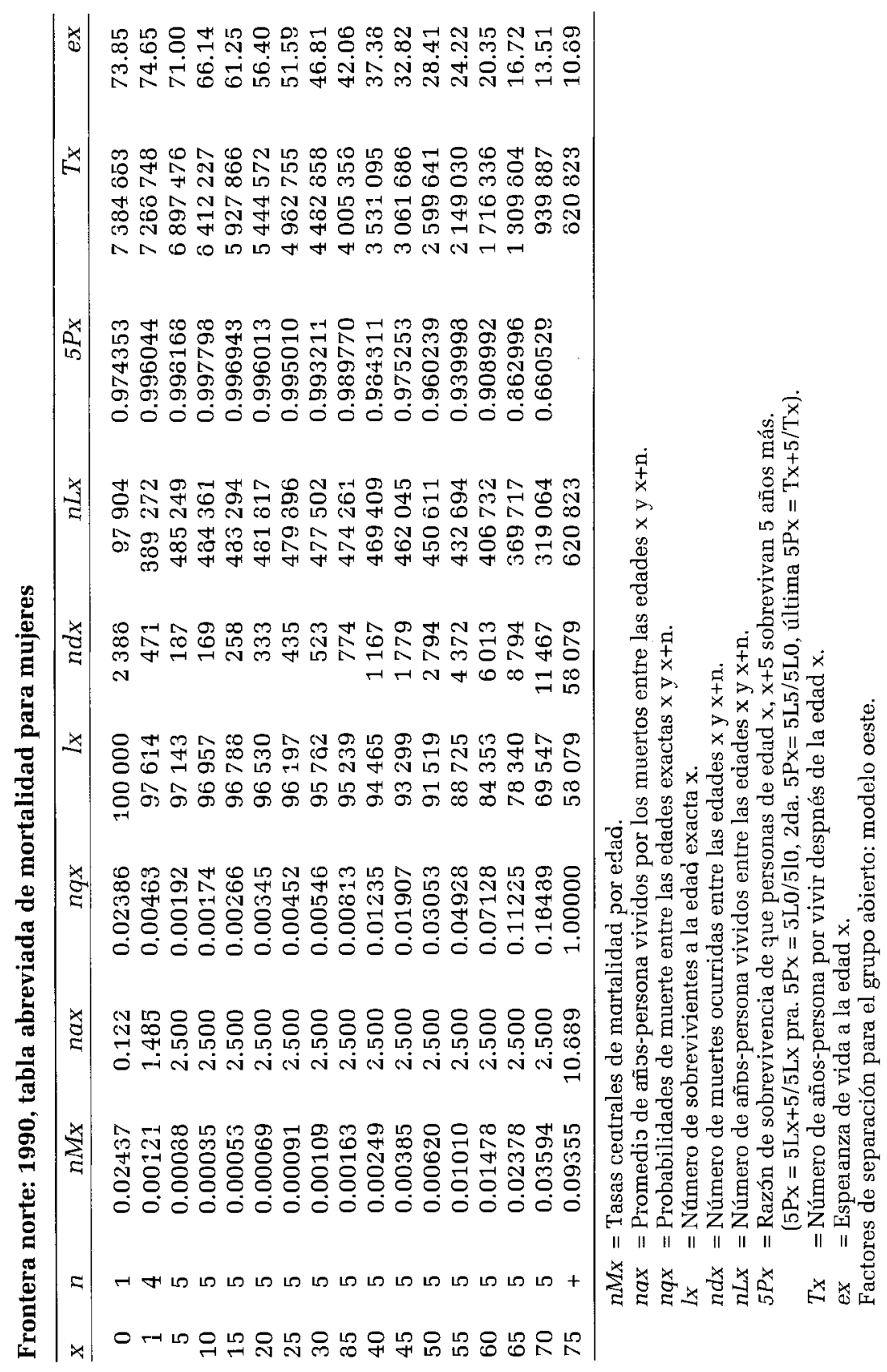


